\title{
REVIEW
}

\section{How to assess epidemiological studies}

\section{J H Zaccai}

Postgrad Med J 2004;80:140-147. doi: 10.1136/pgmi.2003.012633

Assessing the quality of an epidemiological study equates to assessing whether the inferences drawn from it are warranted when account is taken of the methods, the representativeness of the study sample, and the nature of the population from which it is drawn. Bias, confounding, and chance can threaten the quality of an epidemiological study at all its phases. Nevertheless, their presence does not necessarily imply that a study should be disregarded. The reader must first balance any of these threats or missing information with their potential impact on the conclusions of the report.

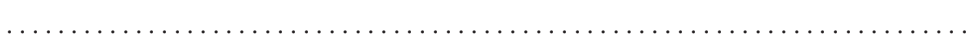

Correspondence to: Ms Julia H Zaccai, Institute of Public Health, University of Cambridge, Forvie Site, Robinson Way Cambridge CB2 2SR, UK; jhz21@cam.ac.uk

Submitted 14 July 2003 Accepted 12 August 2003

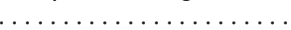

E pidemiology underpins good clinical research. It is any research with a defined numerator, which describes, quantifies, and postulates causal mechanisms for health phenomena. ${ }^{1}$ Epidemiology gives insight into the natural history and causes of disease and can provide evidence to help prevent occurrence of disease. It promotes effective treatments either to cure or to prolong the lives of those with disease. Epidemiology, also referred to as "population medicine", is used to estimate the individual risk of disease and the chances of avoiding it from group experience averages. Such information is crucial to planning interventions and allocating resources.

The epidemiological approach needs to be applied to clinical research to evaluate both its effectiveness and its importance. Hence clinicians need to gain the skills that will allow them to properly update and re-evaluate their knowledge and thus provide the best evidence based patient care. Epidemiology is an interdisciplinary field that draws its techniques and methodologies from biostatistics, social sciences, and clinical medicine as well as from a vast range of biological sciences such as genetics, toxicology, and pathology $y^{2}$ and for this reason the interpretation of epidemiological studies is not always easy.

There are several reviews and books available that provide advice on how best to assess epidemiological studies. The favoured outline for these is by listing types of common errors. This review provides an alternative approach that it is hoped will be helpful. After briefly characterising the main threats to the quality of epidemiological studies, a map is provided to assess studies based on their usual format - that is, the design, conduct, and analysis of the results. Readers of epidemiology papers at any level will be assisted in their task by Last's
A Dictionary of Epidemiology, an essential guide to all. ${ }^{1}$ Assessing the quality of epidemiological studies equates to assessing their validity.

\section{CONCEPT OF VALIDITY AND ITS THREATS}

According to Last, validity is the "degree to which the inference drawn from a study is warranted when account is taken of the study methods, the representativeness of the study sample, and the nature of the population from which it is drawn". ${ }^{1}$ The concept of validity was further developed in the 1950s by Campbell when he introduced the distinction between external and internal validity ${ }^{3}$ :

- Internal validity is the extent to which systematic error is minimised during all stages of data collection.

- External validity is the extent to which results of trials provide a correct basis for generalisation to other circumstances; this is regarding patients, treatment regimens, setting, modalities of outcome, which include definition of outcomes and duration of follow up.

Every step in a study should be undertaken in such a way as to maximise its validity. There are three threats to validity: bias, confounding, and chance.

\section{Bias}

Bias is a systematic error. Sackett has listed dozens of biases that can distort the estimation of an epidemiological measure. ${ }^{4}$ The distinction among these is occasionally difficult to discern but there are two general types of bias that should be remembered: selection bias and information bias. Selection bias is error due to systematic differences in characteristics between those who take part in a study and those who do not. Information bias, also called measurement bias, is systematic error arising from inaccurate measurement (or classification) of subjects on study variable(s). Measurement bias can arise from the choice of tools one uses to measure as well as the assessor's attitude and the cooperation of the participant, if it is a human based study.

Bias in studies does not necessarily mean that they become scientifically unacceptable and should be disregarded. A first step must be to assess the probable impact of the described biases on study results ${ }^{5}$ - that is, the direction in which each bias is likely to affect outcome, and its magnitude. The magnitude should not be so great that the results are changed to make the relationship stronger or weaker than that observed. Unfortunately, there is no simple formula for assessing biases: each must be 


\section{Box 1: Definition}

- Epidemiology is a science, which describes, quantifies, and postulates causal mechanisms for health phenomena in a population.

- The epidemiological approach needs to be applied to clinical research to evaluate effective research.

considered on its own merit in the context of the study population.

\section{Confounding}

Confounding is a type of bias but it is often considered as its own entity. According to Last ${ }^{1}$ :

"Confounding bias is a distortion of the estimated effect of an exposure on an outcome, caused by the presence of an extraneous factor associated both with the exposure and the outcome, that is, confounding is caused by a variable that is a risk factor for the outcome among non-exposed persons and is associated with the exposure of interest, but is not an intermediate step in the control pathway between exposure and outcome".

Confounding is illustrated in fig 1 . Another way of viewing confounding is as a confusion of effects. ${ }^{6}$ The distortion introduced by a confounding factor can be large and it can lead to overestimation or underestimation of an effect, depending on the direction of the associations that the confounding factor has with exposure and disease. Confounding can even change the apparent direction of an effect. $^{6}$

Methods to prevent confounding include randomisation, restriction, and matching. Random allocation, not to be confused with haphazard assignment, can be used in trials. It follows a predetermined plan and aims, within the limits of chance variation, to make the control and experimental groups similar at the start of an investigation, thus minimising any unbalanced relationship between known and unknown confounders and other studied variables. ${ }^{1}$ This is because confounding cannot occur if potential confounding factors do not vary across groups. ${ }^{7}$ In a similar manner, restriction and matching also try to make the study group and comparison group comparable with respect to extraneous factors but this time by specifically selecting subjects according to their "confounder-bearing" status. ${ }^{1}$ For instance, continuing with the example above, the study groups could be chosen in such a way as to include only nonsmokers or only smokers. ${ }^{6}$ Confounding can also be adjusted

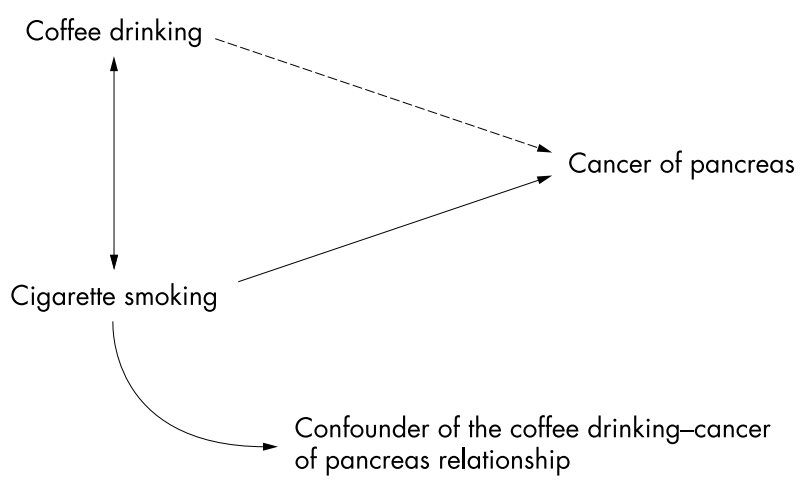

Figure 1 Cigarette smoking as a confounder of the coffee drinkingcancer of pancreas relationship. for during the statistical analysis phase of the study with stratified analysis and multivariate analysis techniques. Stratification is a technique that involves the evaluation of association between the exposure and disease within homogeneous categories or strata of the confounding variable. The results from the above study can be analysed according to smoking history: never smoker, ex-smoker 10+ years, ex-smoker $<10$ years, current smoker. ${ }^{7}$ Multivariate analysis involves the construction of a mathematical model and allows for the efficient estimation of measures of association while controlling for a number of confounding factors simultaneously, even in situations where stratification would fail because of insufficient numbers. ${ }^{7}$

The reader can thus assess confounding by considering whether any important factors have not been taken into account in the design and/or analysis phase of a study, based on an understanding of the natural history of a disease.

\section{Chance}

Inevitably, because studies cannot include entire populations and continue indefinitely in time, some chance factor may result in study outcomes not representing the ultimate true values, even if bias and confounding are non-existent. Investigators adjust for the chance factor using statistics in the analysis phase of the study. However, variations from the true values will be minimised the larger and/or the longer the study.

\section{ASSESSING THE DESIGN AND CONDUCT OF AN EPIDEMIOLOGICAL STUDY \\ Choice of study design \\ Which study design was chosen and was it appropriate?}

Researchers have a choice of several study designs for their investigation and a judgment must be made as to whether their choice is reasonable in relation to the question they wish to consider. Table 1 lists epidemiological study designs and specific goals these can help achieve.

The more appropriate the study design, the more convincing the evidence that will be produced. Conclusions from a case-control study assessing the efficacy of a surgical procedure will be stronger than that of a observational cohort study and will be weaker than that of a well conducted randomised controlled trial.

The reader must beware not to accept what the study claims to be without going through the description of its design. Particularly interventional studies that are described as randomised controlled trials do not always stand up to careful scrutiny. This may be because there is pressure to overclaim the design of a study considered to be the gold standard in epidemiological investigations, which is difficult to conduct in a valid way.

\section{Choice of study population}

Has the population been sufficiently described?

It is important that researchers report the sociodemographic characteristics of the study population to allow readers to see the possibilities of generalisation to other populations. Furthermore, it allows physicians to judge whether they can apply the results to particular patients. ${ }^{9}$ In some instances of case-control studies and trials, the description

\section{Box 2: Threats to validity}

- Bias, confounding, and chance can distort the results of epidemiological studies. 
Table 1 Description of epidemiological study designs (adapted from Detels ${ }^{8}$ )

\begin{tabular}{|c|c|c|c|}
\hline Name & Aims and key aspects of design & Advantages & Disadvantages \\
\hline Ecological studies & $\begin{array}{l}\text { Document the co-occurrence of } \\
\text { disease and other factors in a } \\
\text { population using existing statistics }\end{array}$ & $\begin{array}{l}\text { Cheap. Relatively easy to conduct. } \\
\text { Provide rationale for undertaking } \\
\text { more expensive analytical studies }\end{array}$ & $\begin{array}{l}\text { Risk factors and disease may not } \\
\text { be occurring in the same people }\end{array}$ \\
\hline Cross sectional surveys & $\begin{array}{l}\text { Establish the magnitude of disease } \\
\text { and factors in a community by } \\
\text { collecting data }\end{array}$ & $\begin{array}{l}\text { Can document the co-occurrence of } \\
\text { disease and suspected risk factors in } \\
\text { specific individuals. Useful for studying } \\
\text { chronic diseases which have a high } \\
\text { prevalence* but an incidence* that is } \\
\text { too low to make a cohort study feasible }\end{array}$ & $\begin{array}{l}\text { Expensive. Subject to problems of } \\
\text { information and measurement bias } \\
\text { and uncontrolled confounders. Not } \\
\text { useful for studying diseases with } \\
\text { low prevalence/short courses. } \\
\text { Unless historical information is } \\
\text { obtained from all the individuals } \\
\text { surveyed, the time relationship } \\
\text { between the factor and the disease } \\
\text { is not known }\end{array}$ \\
\hline Case-control studies & $\begin{array}{l}\text { Compare the prevalence of } \\
\text { suspected causal factors in cases and } \\
\text { controls and identify associations }\end{array}$ & $\begin{array}{l}\text { Can estimate odds ratio*. Cheaper } \\
\text { and easier to perform than cohort } \\
\text { and experimental studies. Method } \\
\text { of choice for studying rare diseases. } \\
\text { Indicated when a specific health } \\
\text { question needs to be answered quickly }\end{array}$ & $\begin{array}{l}\text { Cannot measure risk*. Very prone } \\
\text { to selection bias and recall bias. } \\
\text { Not useful for determining a } \\
\text { spectrum of health outcomes } \\
\text { resulting from specific exposures } \\
\text { (since a definition of a case is } \\
\text { required in order to perform the } \\
\text { study) }\end{array}$ \\
\hline Cohort studies & $\begin{array}{l}\text { Measure risk* of disease association } \\
\text { with exposure to a factor in a } \\
\text { prospective design }\end{array}$ & $\begin{array}{l}\text { Can establish the temporal } \\
\text { relationship between an exposure } \\
\text { and a health outcome. Can determine } \\
\text { spectrum of disease resulting from } \\
\text { exposure to a given factor }\end{array}$ & $\begin{array}{l}\text { Expensive and time consuming. } \\
\text { Subject to confounding. Prone to } \\
\text { loss to follow up. Can have } \\
\text { complications in the analysis when } \\
\text { exposure varies over time. Not } \\
\text { feasible for diseases with low } \\
\text { incidence*. Do not prove causality }\end{array}$ \\
\hline $\begin{array}{l}\text { Experimental studies/ } \\
\text { intervention studies/ } \\
\text { clinical trials }\end{array}$ & $\begin{array}{l}\text { Provide strong evidence, if not } \\
\text { proof, of a causal relationship } \\
\text { between an exposure factor } \\
\text { and disease }\end{array}$ & $\begin{array}{l}\text { Offen considered as providing the most } \\
\text { reliable evidence from epidemiological } \\
\text { research. Confounding factors that may } \\
\text { have led to the subjects being exposed in } \\
\text { cohort studies are not a problem here as } \\
\text { investigators make the decision about who } \\
\text { will be exposed to the factor based on the } \\
\text { specific design factors to be employed (for } \\
\text { example random allocation, matching) }\end{array}$ & $\begin{array}{l}\text { Expensive. Can cause ethical } \\
\text { problems in human studies }\end{array}$ \\
\hline \multicolumn{4}{|c|}{$\begin{array}{l}\text { "Incidence: number of instances of illness starting, or of persons falling ill, during a given period in a specified population.' } \\
\text { Odds ratio': exposure odds ratio - the ratio of the odds in favour of exposure among cases to the odds in favour of exposure among non-cases; disease odds } \\
\text { ratio-the ratio of odds in favour of disease among the exposed to the odds in favour of disease among the unexposed. } \\
\text { Prevalence: number of events - for example, instances of a given disease or other condition, in a given population at a designated time.' } \\
\text { Risk: the probability that an event will occur-for example, that an individual with become ill or die within stated period of time or by a certain age or with a certain } \\
\text { exposure to a risk factor.' }\end{array}$} \\
\hline
\end{tabular}

of the group allows assessment for selection bias-that is, differences in the two groups at baseline, which may account for effects observed in the analysis phase. This assessment must also be done even in randomised trials where systematic bias is eliminated. Randomisation does not necessarily produce perfectly balanced groups with respect to prognostic factors and differences due to chance remain in the intervention groups. Assessment of selection bias is crucial and if identified will need to be controlled for during the analysis phase, although in some examples this will not be possible.

\section{What is the source population?}

The source of the population is known to have an impact on the conclusions of a study. For example, selection bias introduced by referral of patients from care centres can affect profoundly the results of clinical and epidemiological studies. ${ }^{4}$ This is because referral is influenced by more than the severity of the disorder itself and has much to do with the way that communities contain and deal with aberrant behaviour. ${ }^{10}$ Referral may differ according to burden of symptoms, access to care, popularity of disorders and institutions. Another example is with participants recruited via the media. Those who volunteer to participate are likely to differ from non-participants in a number of important ways, including basic levels of motivation and attitudes towards health. As a further example, the readers should judge whether recruiting via telephone or door knocking or whether incentives were given to take part in a study will affect the final results, and if so, in what direction.

\section{How were the participants selected?}

The inclusion and exclusion criteria for subject participation and the ways in which they were applied must be clearly defined. This is to show minimum tampering of subject participation by researchers. A common error is defining studies as population based. However, as long as participants have not been recruited from all subgroups of a population, one cannot consider the study to be community based. For example, solely recruiting from health registries would only be acceptable in a country where health care is universal and free. Another important source of effect on the outcome is whether subclinical cases have been included. The readers must always consider how non-included members may affect the results of the study. 
Have the investigators strived for high participation rates?

Investigators must strive for high participation rates. If, for example, the researcher contacts an initial target population and manages to recruit $65 \%$ to take part in his/her study, one must assess whether these $65 \%$ are representative of the initial population. In addition, the investigator must assess whether the numbers recruited are large enough to make statistically viable conclusions. As mentioned earlier, the role of chance on results can be minimised and the generalisability can be maximised in larger and/or longer trials.

Has attrition been high enough to change the main characteristics of the study and control groups?

In the same manner, any attrition or loss to follow up should be reported with an attempt to explain what differences this makes to conclusions.

\section{Has there been any participant exclusion after recruitment?}

Exclusion numbers should be reported. Exclusion is acceptable if study personnel made errors in the implementation of eligibility criteria or if patients never received the intervention in an experimental study. ${ }^{11}$ However, in no circumstance should exclusion be accepted if it appears to be dependent on the treatment given. In trials, post-randomisation exclusion acceptability really depends on whether the goal of study is to address an explanatory (efficacy) or management (effectiveness) question. ${ }^{11}$ Not excluding participants who did not follow their intended treatment will allow an answer to an effectiveness investigation on an intention to treat basis. Only $13 \%$ of all randomised trials published in the New Zealand Medical Journal between 1943 and 1995 provided evidence that final analyses were conducted on an intention to treat basis. ${ }^{12}$ Investigators should clearly state the number of patients recruited but not included in the primary analysis of data and explain the circumstances under which such patients were enrolled but excluded from the analysis.

\section{Which comparison group?}

Any differences between the exposed and control group during the study should be assessed in relation to their potential effect on outcomes observed. Unless this is done adequately, any analysis will be dangerously misleading.

Some investigators feel that the closer the identity of the compared groups with respect to all measurable factors, the greater the validity, since some factors may affect disease incidence without the investigator's awareness. ${ }^{6}$ Matching unexposed to exposed subjects in cohort studies can prevent confounding of the crude risk difference and ratio because such matching prevents the association between exposure and the matching factors among the study subjects at the start of the follow up. ${ }^{6}$ Matching in cohort studies though is rarely done. In practice much of the controlling in cohort studies occurs in the analysis phase where complex statistical adjustment is made for baseline differences in key variables. Matching in case-control studies may introduce bias and thus matching on a factor may still necessitate its control in the analysis phase. ${ }^{6}$ If controls are selected to match cases on a factor that is correlated with the exposure, than the crude exposure frequency in controls will be distorted in the direction of similarity to that of the cases, creating a risk of over matching.

The choice of comparison groups can also introduce error in experimental studies. For example in a meta-analysis showing that research sponsored by the drug industry was more likely to produce results favouring the product made by the company sponsoring the research than studies funded by other sources, ${ }^{13}$ it was shown that this might be due to inappropriate comparators or publication bias rather than the reported quality of methods. It was found that in trials of psychiatric drugs, the comparator drug is often given in doses outside the usual range. Similarly, research funded by the company marketing fluconazole compared it with the oral amphotericin B, a drug known to be poorly absorbed, thereby creating a bias in favour of fluconazole. ${ }^{13}$

Often the comparison is a placebo controlled group, meaning that the control participants were given an inert medication or procedure that is intended to give them the perception that they are receiving treatment for their complaint. ${ }^{1}$ This is thought to control for the power of suggestion by a medical adviser. Hrobjartsson and Gotzsche investigated patient reported and observer outcomes and found no evidence that placebo interventions in general have clinically important effects, except possibly on subjective continuous outcomes, such as pain, where the effect could not be clearly distinguished from bias. ${ }^{14}$ The placebo effect can thus help compare the validity of the methods of investigation in experimental studies. In a review of trials looking at the treatment of irritable bowel syndrome (IBS), the placebo response was extremely variable and high, most frequently between $40 \%$ and $70 \% .^{15}$ Differences of this magnitude reflect not only the nature of the patients enrolled in a trial but also the methods used to determine treatment response. It is a useful way to compare methods and results across studies.

If necessary, has the method of randomisation and allocation concealment been reported?

The non-reporting of the method of randomisation and allocation concealment is one of the main errors in articles reporting randomised trials. For example, a review reported that the mechanism used to allocate interventions was omitted in reports of $93 \%$ of trials in dermatology, $89 \%$ of trials in rheumatoid arthritis, $48 \%$ of trials in obstetrics and gynaecology journals, and $45 \%$ of trials in general medical journals. ${ }^{9}$ Unless stated clearly in the paper, one cannot be assured that randomisation was correctly done. Correct randomisation is dependent on proper allocation concealment-that is, random allocation without foreknowledge of treatment assignments. Methods of concealment include sequentially numbered, opaque, sealed envelopes or containers, can be pharmacy controlled, or completed by central randomisation. However, each may not be sufficient. Elements convincing of concealment must be reported in the study paper. This is crucial as results of four empirical investigations reported by Schulz and Grimes have shown that trials that used inadequate or unclear allocation concealment compared with those that used adequate concealment, yielded up to $40 \%$ larger estimates of effect. ${ }^{9}$

\section{Choice of exposure and outcome measures}

One major source of error in studies, especially in cohorts, is in the degree of accuracy with which respondents have been classified with respect to their exposure and disease statusthat is, measurement bias. Choosing what and how measurements will be collected, whether it be exposure, outcome and other auxiliary variables, determines the validity of the study. If the mis-measurement is random, the misclassification of a dichotomous exposure is always in the direction of the null value. Although it is generally considered acceptable to underestimate effects rather than overestimate them, this type of error may account for some discrepancies amongst studies.

Has potential bias from the choice of tools for data collection been dealt with?

Two types of data can be used for epidemiological studies: routine data and data which have been collected specifically 
for the study. Creating new knowledge versus using routine data has a great impact on any study. Routine data have the advantage of being collected independently of the study and thus an automatic blinding of assessors is in place. However, routine data are often incomplete and not necessarily appropriate for answering the study question.

There are many tools for collecting data. These include open group discussions, self rating, direct examination interviews, and biological marker measurement. Data should be collected in as objective, reliable, accurate, and reproducible fashion as possible. Different data collection methods are prone to different errors of measurement. Hence the use of well recognised standards or validated tools is a positive point. Validity here is an expression of the degree to which a measurement measures what it purports to measure. ${ }^{1}$ Validated questionnaires are especially useful while trying to measure symptomatic effects (such as pain), functional effects (mobility), psychological effects (anxiety), or social effects (inconvenience) of an intervention ${ }^{16}$ as these variables are particularly subjective.

The choice of measurement tools invariably affects results and the readers must understand the impact of this choice. For example, while looking at treatment of IBS, what differences in case definition could be expected from the use of the Manning criteria or using defined one, two, or three symptoms of IBS as entry criteria? Although the Manning criteria are still used, a report studying the diagnostic value of the criteria found it to be considerably more reliable for the diagnosis of IBS in women than in men. ${ }^{17}$ The reader should judge whether this sex bias in case definition could have significantly changed the outcome of the study. Many conditions are complex and clinical or research criteria require the presence of particular symptoms and signs, each of which is associated with the need for an operational decision. Unfortunately, availability of gold standards is an issue for many disorders.

Has enough or too much information been collected? Correct case classification can involve varying effort. For example, the clinical diagnosis of Alzheimer's disease is one of exclusion. Cerebrospinal fluid and blood analyses and imaging are used to differentiate Alzheimer's disease from other illnesses that may cause the same clinical symptoms. Possibly, the more the tests carried out, the less likely a participant would be classified as having Alzheimer's disease.

How long have the participants been followed up? Contestably, many trials are based on limited follow up but are applied as long term therapy. Timing is important. This is especially so in the investigation of effects of treatment of chronic conditions such as Crohn's disease, which has unpredictable periods of exacerbation and remission. Participants should be followed up for a reasonably realistic time period to establish whether a treatment is effective. In a similar manner, research on the potential increase in temporal lobe brain tumours among mobile phone users needs to allow for several years after the beginning of exposure before measuring whether electromagnetic fields can have an effect.

Has potential bias from observers been dealt with? The use of standardised questionnaires or laboratory protocols does not always prevent observer variation. Discrepancies between repeated observations by the same observer and between different observers are to be expected. ${ }^{1}$ This variation is measured by the kappa factor, which allows for chance association. Reporting of kappa values shows a will for validity by the investigators. The higher the factor, the higher the concordance is between measurements. Negative kappa values may be due to faulty techniques or incorrect recording of the results. Misinterpretation of data can be due to the pre-judgment and expectancy of what results should be. This highlights the importance of "blinding" the measurer to the probable caseness of the measured subject and of observing quality controls in carefully agreed protocols. Although often considered free of bias, molecular work is not immune to measurement bias. For example, while comparing tangle determination in the CERAD protocol for neuropathologically diagnosing Alzheimer's disease, Mirra and co-workers found that only $66 \%$ of raters from 15 laboratories showed internal consistency. ${ }^{18}$ It is difficult to assess whether low inter-rater/intrarater reliability can have an effect other than random on the results. However, a minimum aim is to report this reliability for readers to assess the validity of the results.

\section{Has potential bias from the participants been dealt} with?

Bias can result from inaccurate reporting by participants. This is particularly so in case-control studies as the information on exposure is often provided by the participant after the onset of disease. Recall bias can occur when cases differ with respect to their exposure response due to the disease experience relative to controls. For instance, those who have suffered from food poisoning may remember their meals differently from those who did not suffer similarly. The use of memory aids can help reduce recall bias.

There are also circumstances where participants perceive social pressures to report fittingly. This is especially so when dealing with self report on drinking, ${ }^{19}$ smoking, ${ }^{20} 21$ drug taking, and sexual habits. ${ }^{22}$ For example, the reader should judge how self report over the telephone to monitor overweight and obesity in populations can be affected by social desirability. It was found that body mass index, based on measured weights and heights, classified $62 \%$ of males and $47 \%$ of females as overweight or obese, compared with $39 \%$ and $32 \%$ respectively from self report. ${ }^{23}$ Blinding of the participants to study goals and participants' classification status to any interests may help.

\section{ASSESSING THE ANALYSIS PHASE OF AN EPIDEMIOLOGICAL STUDY}

\section{Statistical analysis versus biological interpretation}

Most epidemiological studies results are analysed using formal statistics. The type of statistical test that should be used is determined by the goal of the analysis (for example, to compare groups, to explore an association, or to predict an outcome) and the types of variables used in the analysis (for example, categorical, ordinal, or continuous variables). ${ }^{24}$ The statistical results are often presented with a p value, which is the probability of obtaining an outcome in the study sample as extreme from the null hypothesis as that observed, simply by chance, but more often with a point estimate and confidence intervals, a range within which, assuming there is no bias in the study method, the two values for the population parameter might be expected to lie. ${ }^{5}$ Confidence intervals are more useful to consider than $\mathrm{p}$ values when assessing whether results are significant as they reflect both

\section{Box 3: Study design and conduct}

- The main aspects of the study design and conduct that need to be assessed include: choice of study design, choice of study population, and the choice of exposure and outcome measures. 
Table 2 Example of the cause effect relationship with the human papillomavirus (HPV) and cervical cancer (adapted from Bosch et $a^{27}$ )

\begin{tabular}{|c|c|}
\hline Criterion & HPV-cervical cancer example \\
\hline $\begin{array}{l}\text { Sufficient strength } \\
\text { of association }\end{array}$ & $\begin{array}{l}\text { The association between HPV DNA in cervical } \\
\text { specimens and cervical cancer is one of the } \\
\text { strongest ever observed for a human cancer. } \\
\text { HPV- } 16 \text { accounts for almost } 50 \% \text { of the types } \\
\text { identified in cervical cancer. The cancer risk } \\
\text { for any one of at least } 10 \text { HPV types or for any } \\
\text { combination of HPV types does not differ } \\
\text { significantly }\end{array}$ \\
\hline
\end{tabular}

Temporal relationship between exposure and outcome

Dose-response relationship

Consistency

Biological plausibility and coherence

Analogy

The HPV and cervical cancer model is analogous to many other examples of papillomavirus induced papillomas and carcinomas and cancers caused by other viruses

Table 3 Relative and attributable risks of mortality from lung cancer and coronary heart disease among cigarette smokers in a cohort study of British male physicians (adapted from Doll and Peto ${ }^{28}$ )

\begin{tabular}{lll}
\hline & \multicolumn{2}{l}{ Annual mortality rate/100 000} \\
\cline { 2 - 3 } & Lung cancer & Coronary heart disease \\
\hline Cigarette smokers & 140 & 669 \\
Non-smokers & 10 & 413 \\
Relative risk & 14.0 & 1.6 \\
Attributable risk & $130 / 10^{5} /$ year & $256 / 10^{5} /$ year \\
\hline
\end{tabular}

the degree of variability in the factor being investigated and the limited size of the study: the wider the confidence intervals, the less powerful the study is.

Often, a p value under or equal to a probability of 1 in 20 or 0.05 is considered statistically significant, however, significance does not mean that the results make biological sense. Results can be statistically significant without being biologically/sociologically significant. For example, a very large clinical trial can provide a significant result on the effect of a specific drug that increases the concentration of haemoglobin by $1 \mathrm{~g} / 100 \mathrm{ml}$ blood. The readers should consider whether this is plausible and whether this can have a useful medical effect.

Often the need for large sample sizes to achieve sufficient power and thus precision to answer study hypotheses can lead to combination of broad categories of cases. This can cause heterogeneity in the cases groups, which can be inappropriate. ${ }^{25}$ This happens in cohort studies and the result is that it can obscure effects on more narrowly defined diseases. However, such non-differential misclassification of exposure, even if substantial, only underestimates associations, provided that the misclassification probabilities apply uniformly to all subjects. ${ }^{6}$

\section{Have the results shown a cause-effect relationship?}

Showing that an exposure is strongly associated with a disease does not necessarily imply that there is a cause-effect relationship. Hill described a series of conditions, which if completed will prove a cause-effect relationship. ${ }^{26}$ These are:

- A sufficient strength of association.

- A temporal relationship between exposure and outcome.

- A dose-response relationship.

- Consistency.

- Biological plausibility.

- Coherence.

- Specificity.

- Analogy.

Temporality is particularly difficult to demonstrate in casecontrol studies where all data are collected at once. Table 2 shows these criteria illustrated using the cause effect relationship described for the human papillomavirus and cervical cancer. ${ }^{27}$

\section{What are the policy implications?}

The final phase of assessing epidemiological studies is determining whether it has any policy implications. Although a consistency and magnitude of effect can be demonstrated, the impact of any intervention must also be considered. This is also known as the generalisability of the results and is directly dependent on the study participants' characteristics.

To assess the impact of an intervention, the reader should also think in terms of attributable risk rather than relative risk. Attributable risk is the proportion of a disease or other outcome in exposed individuals that can be attributed to the exposure. This measure is derived by subtracting the rate of

\section{Box 4: Aspects of study analysis to be assessed}

- Aspects of the study analysis phase which need to be assessed are the statistical and biological interpretation of the results, the generalisability of the findings, and whether they show a cause-effect relationship between the factors under investigation. 
Box 5: Balance of threats and impact of conclusions

- The reader must balance any threat described regarding the quality of the study and any missing information with their potential impact on the conclusions of the report.

the outcome (usually incidence or mortality) among the unexposed from the rate among the exposed individuals. ${ }^{1}$ It is assumed that causes other than the one under investigation have had equal effects on the exposed and unexposed groups. This is different to the relative risk, which is the ratio of the risk of disease or death among the exposed to the risk among the unexposed. ${ }^{1}$ The relative risk provides information that can be used in making a judgment of causality. However, once causality is assumed, from the perspective of public health policy making, measures of association based on absolute differences in risk between exposed and nonexposed individuals assume far greater importance. This is illustrated with the example in table 3.

\section{CONCLUSION}

There are many subjective elements to the interpretation of epidemiological studies; however, minimum standards in the conduct of a study ensure that any conclusion reached is appropriate. The reader must bear in mind that assessing an epidemiological study not only implies knowing how to look for key information in its paper but also in its "comments" and "corrections". These are listed along with the paper reference in Medline. Bias, confounding, and chance can threaten the validity of a study at all its stages. Thus, the methodology must be well thought-out and this must be reflected in the study paper. It is understood that all the details about choices made by investigators cannot be published; nevertheless, the printed information should provide sufficient details so as to rule out alternative interpretations of the results. Investigators must show that they planned to minimise bias and account for confounding while also describing statistical methods. More importantly though, they must report any potential impact of limitations on the results found. Many reviewers when assessing study validity take a "guilty until proved innocent approach", where one assumes that the quality is inadequate unless the information to the contrary is provided in the text. ${ }^{3}$ This can

\section{Box 6: Key reading}

- Last JM. A dictionary of epidemiology. 4th Ed. Oxford: Oxford University Press, 2001.

- Greenberg RS, et al.Medical epidemiology. 3rd Ed. Lange Editions, 2001 (chapter 13).

- Coggan D, Rose G, Barker DJP. Epidemiology for the uniniated. 4th Ed. London: BMJ Publishing Group, 1997 (an excellent concise introduction).

- Bhopal R. Concepts of epidemiology: an integrated introduction to the ideas, theories, principles and methods of epidemiology. Oxford: Oxford University Press, 2002 (comprehensive and up-to-date).

- Hennekens $\mathrm{CH}$, Buring JE. Epidemiology in medicine. Little, Brown, 1987 (good introduction to medical statistics).
Questions (true (T)/false (F); answers at end of references)

(1) Confounding occurs when an exposure causes its effect through a second exposure.

(2) Potential for selection and recall bias is a particular problem in cohort studies as opposed to other analytic designs because both exposure and disease have already occurred at the time information on study subjects is obtained.

(3) The results of an investigation carried out on volunteer participants can be expected to the same as those from participants chosen from case registries.

(4) Risk is another term for odds ratio.

(5) Matching should be used to control for selection bias in epidemiological studies.

be a dangerous tactic and may exclude many valid studies. The reader should take the same approach as described for dealing with potential bias and confounding and balance any missing information with its potential impact on the conclusions of the report.

\section{REFERENCES}

1 Last JM. A dictionary of epidemiology. 4th Ed. Oxford: Oxford University Press, 2001

2 Friis RH, Sellers TA. Epidemiology for public health practice. Gaithersburg, MD: Aspen, 1996.

3 Juni $\mathbf{P}$, Altman DG, Egger M. Assessing the quality of controlled clinical trials. BMJ 2001;323:42-6.

4 Sackett DL. Bias in analytic research. J Chronic Dis 1979;32:51-63.

5 Coggan D, Rose G, Barker DJP. Epidemiology for the uniniated. 4th Ed. London: BMJ Publishing Group, 1997.

6 Rothman KJ, Greenland S. Modern epidemiology. 2nd Ed. Philadelphia, Lippincott-Raven, 1998

7 Hennekens $\mathrm{CH}$, Buring JE. Epidemiology in medicine. Boston: Little, Brown, 1987.

8 Detels R. Epidemiology: the foundation of public health. In: Detels R, et al. eds. Oxford textbook of public health. Oxford: Oxford Medical Publications, 1997:501-6.

9 Schulz KF, Grimes DA. Allocation concealment in randomised trials: defending against deciphering. Lancet 2002;359:614-18.

10 Brayne C. Clinicopathological studies of the dementias from an epidemiological viewpoint. Br J Psychiatry 1993;162:439-46.

11 Fergusson D, Aaron SD, Guyatt G, et al. Post-randomisation exclusions: the intention to treat principle and excluding patients from analysis. BMJ 2002;325:652-4.

12 Neal B, Rodgers A, Mackie MJ, et al. Forty years of randomised trials in the New Zealand Medical Journal. N Z Med J 1996;109:372-3.

13 Lexchin J, Bero LA, Djulbegovic B, et al. Pharmaceutical industry sponsorship and research outcome and quality: systematic review. BMJ 2003;326:1167.

14 Hrobjartsson A, Gotzsche PC. Placebo treatment versus no treatment. Cochrane Database Systematic Review 2003;(1):CD003974.

15 Akehurst R, Kaltenthaler E. Treatment of irritable bowel syndrome: a review of randomised controlled trials. Gut 2001;48:272-82.

16 Greenhalgh T. Assessing the methodological quality of published papers. BMJ 1997;315:305-8.

17 Yamada T, Apers DH, Owyang C, et al. Textbook of gastroenterology. 2nd Ed. Vol 2. Philadelphia: J B Lippincott, 1995.

18 Mirra SS, Heyman A, McKeel D. The Consortium to Establish a Registry for Alzheimer's Disease (CERAD). Part II. Standardization of the neuropathologic assessment of Alzheimer's disease. Neurology 1991:41:479-86.

19 Embree BG, Whitehead PC. Validity and reliability of self-reported drinking behaviour: dealing with the problem of response bias. I Stud Alcohol 1993;54:334-44.

20 Wagenknecht LE, Burke GL, Perkins LL, et al. Misclassification of smoking status in the CARDIA study: a comparison of self-report with serum cotinine levels. Am J Public Health 1992;82:33-6.

21 Shaffer HJ, Eber GB, Hall MN, et al. Smoking behaviour among casino employees: self-report validation using plasms cotinine. Addiction and Behaviour 2000;25:693-704.

22 Crosby RA. Condom use as a dependent variable: measurement issues relevant to HIV prevention programs. AIDS Educ Prev 1998; 10:548-57.

23 Flood V, Webb K, Lazarus R, et al. Use of self-report to monitor overweight and obesity in populations: some issues for consideration. Aust N Z J Public Health 2000;24:96-9. 
24 Greenberg RS, Daniels SR, Flanders WD, et al. Medical epidemiology. 3rd Ed. New York: Lange Medical Books/McGraw Hill, 2001.

25 Zwitter M. A personal critique: evidence-based medicine, methodology and ethics of randomised clinical trials. Crit Rev Oncol Hematol 2001;40:125-30.

26 Hill AB. The environment and disease: association or causation? Proceedings in Social Medicine 1965;58:295-300.

27 Bosch FX, Lorincz A, Munoz N, et al. The causal relation between human papillomavirus and cervical cancer. J Clin Pathol 2002;55:244-65.
28 Doll R, Peto R. Mortality in relation to smoking: twenty years' observations on male British doctors. BMJ 1976;ii: 1525.

\section{ANSWERS}

1. $\mathrm{T} ; 2$. F (it is a particular problem in case-control studies); 3. F; 4. F; 5. F (matching is used to control for confounding).

\section{Clinical Evidence - Call for contributors}

Clinical Evidence is a regularly updated evidence based journal available worldwide both as a paper version and on the internet. Clinical Evidence needs to recruit a number of new contributors. Contributors are health care professionals or epidemiologists with experience in evidence based medicine and the ability to write in a concise and structured way.

\section{Currently, we are interested in finding contributors with an interest in}

the following clinical areas:

Altitude sickness; Autism; Basal cell carcinoma; Breast feeding; Carbon monoxide poisoning; Cervical cancer; Cystic fibrosis; Ectopic pregnancy; Grief/bereavement; Halitosis; Hodgkins disease; Infectious mononucleosis (glandular fever); Kidney stones; Malignant melanoma (metastatic); Mesothelioma; Myeloma; Ovarian cyst; Pancreatitis (acute); Pancreatitis (chronic); Polymyalgia rheumatica; Post-partum haemorrhage; Pulmonary embolism; Recurrent miscarriage; Repetitive strain injury; Scoliosis; Seasonal affective disorder; Squint; Systemic lupus erythematosus; Testicular cancer; Varicocele; Viral meningitis; Vitiligo However, we are always looking for others, so do not let this list discourage you.

\section{Being a contributor involves:}

- Appraising the results of literature searches (performed by our Information Specialists) to identify high quality evidence for inclusion in the journal.

- Writing to a highly structured template (about 2000-3000 words), using evidence from selected studies, within 6-8 weeks of receiving the literature search results.

- Working with Clinical Evidence Editors to ensure that the text meets rigorous epidemiological and style standards.

- Updating the text every eight months to incorporate new evidence.

- Expanding the topic to include new questions once every 12-18 months.

If you would like to become a contributor for Clinical Evidence or require more information about what this involves please send your contact details and a copy of your CV, clearly stating the clinical area you are interested in, to Claire Folkes (cfolkes@bmigroup.com).

\section{Call for peer reviewers}

Clinical Evidence also needs to recruit a number of new peer reviewers specifically with an interest in the clinical areas stated above, and also others related to general practice. Peer reviewers are health care professionals or epidemiologists with experience in evidence based medicine. As a peer reviewer you would be asked for your views on the clinical relevance, validity, and accessibility of specific topics within the journal, and their usefulness to the intended audience (international generalists and health care professionals, possibly with limited statistical knowledge). Topics are usually 2000-3000 words in length and we would ask you to review between 2-5 topics per year. The peer review process takes place throughout the year, and our turnaround time for each review is ideally 10-14 days.

If you are interested in becoming a peer reviewer for Clinical Evidence, please complete the peer review questionnaire at www.clinicalevidence.com or contact Claire Folkes(cfolkes@bmigroup.com). 